\title{
La nueva política de los pobres: Estado, líderes y organizaciones populares en la provisión de servicios básicos. Un estudio de caso en un asentamiento de la Región Metropolitana de Buenos Aires*
}

PATRICIO BRUNO BESANA**

Artículo recibido: 17 de mayo de 2013

Artículo aprobado: 5 de diciembre de 2013

Doi: dx.doi.org/10.12804/desafios26.1.2014.08

Para citar este artículo: Besana, P. B. (2014). La nueva política de los pobres: Estado, líderes y organizaciones populares en la provisión de servicios básicos. Un estudio de caso en un asentamiento de la Región Metropolitana de Buenos Aires. Desafios, 26 (1), 297-332. doi: dx.doi.org/10.12804/desafios26.1.2014.08

\footnotetext{
* Agradezco a los vecinos del barrio Reconquista y a todos los entrevistados por prestarme parte de su tiempo; al grupo Ambiente y Política por la lectura crítica de versiones previas; a los revisores anónimos de la revista por sus valiosos comentarios; a los doctores Rodrigo Zarazaga y Lucas González por facilitarme desinteresadamente algunas de sus publicaciones; a Eliana Bussi, Gustavo Curuchet, Silvia Grinberg, Luciano Martín Mantiñan y a mi director, Ricardo A. Gutiérrez, con quienes compartí horas de trabajo y junto a quienes coelaboré parte de la información presentada. Vaya para el último, además, un agradecimiento especial por su paciencia y apoyo constante.

** Becario doctoral Conicet tipo II. Miembro del Grupo Ambiente y Política (GAP) de la Escuela de Política y Gobierno de la Universidad Nacional de San Martín (Unsam), partido de General San Martín, provincia de Buenos Aires, República Argentina. Correo electrónico: patriciobesana@hotmail.com
} 


\title{
Resumen
}

Del año 2000 en adelante, la literatura sobre clientelismo en Argentina se ha revitalizado. Los distintos enfoques que la componen suelen privilegiar una de las siguientes dimensiones: a) la importancia que tienen las "redes de resolución de problemas" para los más pobres, o b) lo significativo de la "compra de votos a cambio de favores personales" para el partido clientelista. Sin embargo, pocos planteamientos advirtieron las actividades que algunos punteros comenzaron a asumir con respecto a la provisión de servicios básicos para el conjunto de una comunidad desde los años noventa. En la última década, una nueva politica, marcada por una profusión de programas de financiamiento público ha complejiza ado y pronunciado el fenómeno mediante el surgimiento de organizaciones populares. Algunas de estas organizaciones han sido señaladas como la semilla del movimiento piquetero; no obstante, en este periodo y en el anterior, la literatura no ha reparado en la labor de los actores locales en torno a la prestación de servicios básicos. Mediante un estudio centrado en un asentamiento, el presente tiene dos objetivos: señalar la importancia de los mencionados actores locales en la provisión de servicios y explorar los cambios que han experimentados durante la última década.

Palabras clave: organizaciones populares, líderes locales, Estado, servicios básicos, asentamientos

\section{The New Politics of the Poor: State, Leaders and Popular Organizations in the Provision of Basic Services. A Case Study in a Slum in Buenos Aires}

\begin{abstract}
Since the 2000s the literature on clientelism has been revitalized in Argentina. Most approaches are located between positions that privilege one of the following dimensions: (a) the importance of the "problem-solving network" for the urban poor, or (b) the importance of "vote-buying in exchange for personal favors" for the clientelistic party. However, neither of them points out that some local political brokers undertook. activities regarding the provision of basic services for the entire community since the 1990s. During the last decade, as a result of a new policy, this process bas become more complex and pronounced due to the emergence of new popular organizations funded
\end{abstract}


by publics programs. Some of these organizations have been identified as the seeds of the "piqueteros" movement. However, during this period of time, the literature has not emphasized the work of local actors in terms of the provision of basic services. Utilizing a single-case study focusing on a particular slum, this paper has two goals: (i) to show the importance of the aforementioned local actors in the provision of services; and (ii) to explore the changes they experienced over the last decade.

Key words: popular organizations, local leaders, state, basic services, slums

\section{A nova política dos pobres: estado, líderes e organizações populares na provisão de serviços básicos. Um estudo de caso em um assentamento da Região Metropolitana de Buenos Aires, Argentina}

\section{Resumo}

A partir do ano 2000 a literatura sobre clientelismo na Argentina tem se revitalizado. Os distintos enfoques que a compõem costumam privilegiar uma das seguintes dimensões: a) a importância que têm as "redes de resolução de problemas" para os mais pobres, ou b) o significativo da "compra de votos em troca de favores pessoais" para o partido clientelista. No entanto, poucos enfoques advertiram as atividades que alguns indicadores começaram a assumir com respeito à provisão de serviços básicos para o conjuro de uma comunidade, desde os anos 90, Na última década, uma nova política, marcada por uma forte profusão de programas de financiamento público, tem complexado e pronunciado o fenômeno mediante o surgimento de novas organizaçōes populares. Algumas destas organizações têm sido assinaladas como a semente do movimento piqueteiro. No entanto, neste período como no anterior, a literatura não tem reparado no trabalbo dos atores locais em torno à apresentação de serviços básicos. Mediante um estudo centrado em um assentamento, o presente tem 2 objetivos: destacar a importância dos mencionados atores locais na provisão de serviços, e explorar as mudanças que têm experimentado durante a última década.

Palavras-chave: organiżações populares, líderes locais, estado, serviços básicos, assentamentos 
La población que reside en asentamientos ${ }^{1}$ de la periferia de la Región Metropolitana de Buenos Aires (en adelante RMBA) ha experimentado un crecimiento pocas veces visto (Cravino, Del Río y Duarte, 2007). Factores de distinta índole someten a esta población a condiciones de extrema pobreza y de alta degradación ambiental, dos problemáticas que se refuerzan entre sí (Gutiérrez, 2012). Por un lado, el escaso poder adquisitivo de vastos sectores populares los obliga a localizarse en tierras con poco o nulo valor comercial, sobre todo en áreas inundables o expuestas a riesgos ambientales (Merlinsky, Fernández, Montera y Tobías, 2011). Por otro lado, la falta o inadecuada provisión de servicios básicos (agua potable y cloacas, recolección de residuos, energía eléctrica, etc.) se convierte en un agravante de las condiciones ambientales de los asentamientos (Besana, Grinberg y Gutiérrez, 2011). A diferencia de lo que sucede en los barrios más acomodados del centro metropolitano, donde los servicios son gestionados integralmente por agencias públicas o empresas privadas, en los asentamientos la provisión de servicios es posible solo gracias a la mediación que distintas organizaciones populares y líderes locales realizan entre las agencias públicas y la población beneficiaria (Collier y Handlin, 2009). Hasta fines de los noventa, las organizaciones y los sujetos por excelencia de estas y otras intervenciones eran las unidades básicas (organizaciones de base del Partido Peronista) y sus respectivos punteros políticos o líderes locales peronistas (Levitsky, 2003). Por entonces, Auyero (2001) llamó la atención sobre el lugar de privilegio que las primeras y los segundos ocupaban en lo que denominó "las redes de resolución de problemas del clientelismo peronista" (p. 55). Desde ese momento, el estudio del clientelismo en Argentina se ha revitalizado. La mayoría de los planteamientos suele privilegiar alguna de sus dimensiones más características: a) las "redes de resolución de problemas cotidianos" que el clientelismo significa para la población más pobre, o b) el proceso de "compra de votos" por parte del partido clientelar. Sin embargo, ni los primeros, los segundos o aquellos que se encuentran en medio advirtieron algunas de las actividades que

\footnotetext{
1 Utilizo el término asentamiento para referirme al conjunto de las estrategias de vivienda popular tradicionalmente discriminadas en dos tipos: villas miserias y asentamientos informales.
} 
varios punteros realizaban "más allá del clientelismo" (Zarazaga, s. f.). En otras palabras, se trata del rol que asumieron algunos líderes locales (más allá del intercambio de favores individuales por votos) como prestadores de servicios básicos colectivos.

El primer objetivo del presente trabajo es señalar la importancia que los actores mencionados iban adquiriendo en la prestación de servicios básicos en asentamientos durante la década del noventa.

En los últimos diez años se ha suscitado una serie de cambios: la interacción entre las organizaciones populares o líderes locales y las agencias públicas se ha intensificado y transformado a partir de la mutación de antiguos planes sociales en programas de financiamiento público destinados a la prestación de servicios básicos. ${ }^{2}$ Gran parte de la literatura especializada ha relacionado la profusión de los programas públicos y su relación con las organizaciones populares locales con un proceso de mayor envergadura denominado "burocratización de las organizaciones piqueteras" (Natalucci, 2010; Perelmiter, 2012). Antes de su burocratización, tres cuestiones distinguían al movimiento piquetero o de desocupados: 1) el piquete ${ }^{3}$ como método distintivo y original de protesta; 2) el ejercicio de un trabajo social de base bajo la forma de redes barriales de provisión social, y 3) la autogestión de planes sociales obtenidos de agencias públicas mediante los métodos de protesta (Gómez, 2006; Pereyra, Pérez y Schuster, 2008; Svampa y Pereyra, 2003). A partir de la presidencia de Néstor Kirchner (2003-2007), el proceso de burocratización del movimiento piquetero significó la desmovilización de gran parte de las organizaciones que lo componían, el acceso de algunos de sus referentes al entramado institucional del Estado y la expansión y transformación de los planes

\footnotetext{
2 Puede describirse un largo proceso de sucesión y evolución de programas públicos que se remonta a los primeros planes asistenciales de los años ochenta (como el PAN, Plan País, Plan Vida), los planes Trabajar, Barrios Bonaerenses, Jefes y Jefas Desocupados, planes de vivienda social (como el Programa Federal de Emergencia Habitacional) y aquellos destinados a la prestación de servicios básicos.

3 El piquete es una forma de protesta utilizada en el territorio argentino tras la crisis que sufriera dicho país en el año 2001. Se basa en el corte de calles o rutas y tiene por fin alterar el orden vigente y llamar la atención de las autoridades, los medios y del público en general.
} 
sociales en los programas de financiamiento público antes referidos. Sin embargo, en la mayoría de los casos estos planteamientos incurren en varias omisiones: 1) desconocen las continuidades y rupturas que el proceso significó para las "antiguas" organizaciones populares y líderes locales, señalados por la literatura sobre el clientelismo; 2) no dan cuenta del crecimiento cuantitativo de las organizaciones populares locales, y 3) pasan por alto la importancia que este proceso trajo hacia la provisión de servicios básicos en asentamientos.

El segundo objetivo del estudio es explorar los cambios sufridos por los viejos líderes locales y las organizaciones populares y el surgimiento de nuevos líderes y organizaciones durante la última década, a raíz de la profusión de los programas de financiamiento público. En Argentina, estos programas han sido catalogados como Programas de Transferencia Condicionada (Zarazaga, 2013) o como Programas de Empleo (Díaz Langou, 2012). En todo caso, se ha analizado su distribución en términos clientelares (Brusco, Nazareno y Stokes, 2004; Zarazaga, 2013). Aunque estos análisis subrayan un aspecto importante de la implementación de dichos programas, sostengo que ya no bastan las categorías de análisis que refieren al clientelismo peronista (Auyero, 2001) para describir al conjunto de relaciones entre el Estado y la población que reside en los asentamientos. Tampoco se bastan por sí solos aquellas observaciones sobre la burocratización de las organizaciones piqueteras. Ambos se basan en dos tipos de actores diferentes que, a mi entender, han ido mezclándose hasta confluir, con matices propios de su trayectoria previa, en un fenómeno que denomino la nueva política de los pobres.

La estrategia teórico-metodológica que utilizo combina trabajo de campo etnográfico (2009-2013) en un asentamiento de la periferia de la RMBA, entrevistas espontáneas y semiestructuradas a líderes locales, funcionarios públicos y vecinos del barrio, análisis de documentos públicos y material bibliográfico y 210 encuestas a vecinos del barrio sobre las formas en que acceden a los servicios, sus percepciones sobre los principales problemas locales y sus ingresos mensuales. El relato y las reflexiones finales deben matizarse, en todo momento, a la luz de las limitaciones que presenta todo estudio de caso. 
Sigue a continuación una serie de apartados que describen el contexto histórico en el que aumenta la población que reside en asentamientos de la periferia de la RMBA y las formas como se proveen los servicios básicos (en particular el de agua potable) en todo el territorio de la región y en los asentamientos.

\section{Deterioro de las formas de hábitat popular y proliferación de los asentamientos en la periferia de la RMBA}

La RMBA es el conglomerado urbano más importante de la Argentina. El proceso de urbanización que le dio la forma que tiene hoy día se inició durante de los primeros años del siglo XX (Pírez, 2004). En el marco de dicho proceso, hacia fines de los años veinte, la planificada provisión pública de los servicios básicos alcanzó casi la totalidad de la extensión de la Ciudad Autónoma de Buenos Aires (en adelante CABA), centro de la región (Godelik, 1998, p. 24 citado en Pírez, 2004). Mientras tanto, en los municipios de la provincia de Buenos Aires, periferia de la región, el proceso de urbanización tomó impulso tras los años cuarenta, de la mano del crecimiento de la industria nacional (Collier y Handlin, 2009). Entonces, los pocos asentamientos existentes eran considerados como estrategias de habitación transitoria por parte de quienes se acercaban a la región, atraídos por la demanda de mano de obra y la posibilidad de ascenso social (Verbitsky, 1957).

Durante las tres primeras partes del siglo XX, Argentina y sobre todo la RMBA presentaron indicadores socioeconómicos muy superiores a los de la media del resto de los países de América Latina (Fundación Konrad Adenauer, 2007). Tras la reestructuración del Estado nacional iniciada en los años setenta y consolidada durante la década del noventa, las políticas económicas neoliberales implementadas tuvieron, entre otras consecuencias, el encarecimiento del mercado inmobiliario y la contracción del mercado laboral nacional y metropolitano. Desde entonces, progresivamente, los asentamientos en la periferia de la RMBA pasaron a ser la forma preponderante y definitiva de acceso a la vivienda urbana para los sectores populares (Cravino et al., 2007). Según algunas estimaciones, mientras en 1981 la población que residía en asentamientos representaba un 4,3\% de la población total de la 
RMBA, para 2006 esa cifra aumentaba a 10,1\%, lo que equivale a un crecimiento relativo de $220 \%$ sobre un $35 \%$ del total de la población (Cravino et al., 2007). Al mismo tiempo, la paulatina escasez de terrenos habitables en las cercanías del centro administrativo y comercial de Buenos Aires (CABA), la merma en el poder adquisitivo de los sectores populares y la falta de políticas de vivienda barata para ellos los empujó a localizarse en tierras degradadas ambientalmente, con escaso o nulo valor comercial (Merlinsky et al., 2011). La deficiente provisión de servicios básicos es uno de los principales problemas que a diario deben afrontar los habitantes de los asentamientos. De aquí en adelante, tomo como ejemplo el caso del servicio de agua potable por dos razones: la primera se refiere a que, como se verá en el relato etnográfico, la extensión del servicio de agua potable en el asentamiento analizado dependió de la participación y gestión de un líder local (o puntero peronista, según la literatura sobre clientelismo). La segunda razón tiene que ver con que el servicio de agua potable es de los servicios básicos más complejos de extender (entre otras cuestiones, por las grandes inversiones en infraestructura que requiere) y de los más desigualmente distribuidos. Un análisis histórico de la inequitativa distribución y de las formas de prestación de este servicio en asentamientos me permitirá reconstruir los antecedentes y el contexto en el que surgen algunos de los actuales programas de financiamiento público.

\section{La distribución universal como materia pendiente: el caso de los servicios de agua y saneamiento en la RMBA}

La gestión de los servicios de agua y saneamiento en la RMBA siguió un movimiento pendular (Muñoz, 2005) de privado a público en dos ocasiones. El objetivo manifiesto de todas las gestiones fue la provisión universal del territorio de su competencia; sin embargo, dicho objetivo jamás fue alcanzado. Desde la década del cuarenta del siglo pasado en adelante, los porcentajes de cobertura de la empresa estatal Obras Sanitarias comenzaron a quedar cada vez más rezagados con respecto al ritmo creciente de la urbanización de la región (Catenazzi, 2007). La estratificación socioeconómica de la provisión sería, desde entonces, una característica estructural de la misma. Cuando la propiedad de la empresa pasó a manos de privados, el déficit en la región 
era de un $40 \%$ en agua potable y de un $60 \%$ en desagües cloacales (Azpiazu y Bonofiglio, 2007). Las zonas más afectadas se localizaban en los partidos de la provincia de Buenos Aires, "siguiéndose el patrón histórico de preeminencia del centro sobre la periferia y de los ejes principales de urbanización sobre los espacios intersticiales" (Azpiazu y Bonofiglio, 2007, p. 35).

En 1989, época en que Argentina sufría los efectos de una hiperinflación, se sancionaba la Ley de Reforma Administrativa, que declaraba el estado de emergencia de todos los servicios públicos. Dicha Ley posibilitó una sucesión de privatizaciones de empresas públicas en el marco de lo que se denominó “modernización del Estado". El contrato de concesión de los servicios de agua potable y saneamiento se firmaría entre las últimas privatizaciones en un marco de mayor estabilidad política y económica del país. De ese modo, la empresa privada Aguas Argentinas S. A. (AASA) asumía en 1993 la gestión de los servicios. Según Gerchunof y Casanovas (1995), el escenario macroeconómico — menos apremiante al momento de la concesión que en los casos de privatizaciones previas - permitió que en el contrato se incluyera un objetivo de carácter social como la distribución universal. Empero, los porcentajes de provisión y las zonas provistas a lo largo de la gestión privada denotan que la lógica de la empresa privilegiaba la maximización de las ganancias (Catenazzi, 2007). Los primeros resultados del modelo se manifestaron de varias formas: la empresa siguió una estrategia de segmentación de la cobertura, extendió las redes de servicios a los barrios formales y con capacidad de pago e interpeló al Estado por la falta de servicios en asentamientos, como una cuestión de agenda social. El Estado nacional convalidó la postura de la empresa durante la mayor parte del período que duró la concesión. Así, hasta la renegociación del servicio entre 1997 y 1999, fueron instalándose poco a poco dos modos de provisión: en los barrios formales, las obras ingresaban a los municipios por medio de las direcciones de obras públicas y eran llevadas a cabo por profesionales de la empresa concesionaria; en el caso de los asentamientos, solían ingresar por las direcciones de desarrollo social y dependían de la construcción de asociaciones entre líderes locales u organizaciones 
populares y funcionarios públicos o representantes de la empresa ${ }^{4}$ (Catenazzi, 2007). Tal como se podrá observar en el relato etnográfico, en muchos de los casos documentados (Bolay, Pedrazzini y Da Cunha, 1996; Lazarini, 2007) en que un asentamiento lograba algún tipo de provisión, grupos de vecinos, coordinados por un líder local o no, eran los que hacían la mayor parte de las obras necesarias.

Esta última forma de provisión habría de institucionalizarse tras la renovación del contrato de concesión con el denominado mecanismo participativo de gestión. Según el testimonio de personal jerárquico de la empresa, este espacio funcionaba de la siguiente manera:

[...] Aguas Argentinas ponía los materiales, los vecinos el trabajo y la municipalidad algún material o máquina que hacía falta y la inspección de la obra. Además, los municipios eran los que solían seleccionar los barrios donde se hacían las obras; había siempre ahí algún arreglo político [...] después se llevaban a cabo mesas de gestión, donde se evaluaba el desarrollo de la obra y la empresa también ponía un inspector de obra (personal de la empresa, comunicación personal, 20 de abril de 2011).

En 2001, una nueva crisis nacional daría forma a un contexto en el que se producirían cambios en la gestión de los servicios de agua y saneamiento. Por entonces, la Ley de Emergencia Pública y Reforma del Régimen Cambiario disponía el fin de la convertibilidad y la renegociación de los contratos de concesión. Varios intentos de renegociación entre el Gobierno nacional y AASA precedieron al Decreto 303/06 del año 2006 que daba por finalizada la gestión privada. Según cálculos de Azpiazu (2010), la empresa saliente cumplió tan solo con un 60,9\% de las inversiones estipuladas. Por otro lado, la mayoría de las inversiones tuvo como fin el mantenimiento de las redes existentes y acentuó las diferencias entre las zonas céntricas y periféricas (Ciccollela, 2009, p. 298; Montera, 2012, pp. 7-8). Según cálculos de la empresa entrante,

\footnotetext{
4 En muchos casos, la lógica de la empresa consistía en unirse a reclamos de larga data de los líderes locales por la regularización del dominio de los asentamientos y de esa forma poder cobrarles el servicio (Catenazzi, 2007).
} 
casi 1.497.523 de personas no fueron provistas por el servicio de agua potable, 3.368 .812 por el de cloacas ${ }^{5}$ y 6.180 .000 no recibieron ningún tratamiento para sus afluentes cloacales durante la gestión de AASA (Aguas y Saneamientos Argentinos S. A., 2006).

El Decreto 303/06 declaró que mientras la empresa privada concebía al agua potable "desde una perspectiva de economía de mercado", el Estado lo hacía como "un bien social y cultural", un "derecho humano" (Poder Ejecutivo de la Nación Argentina, 2006). No obstante, en los asentamientos, el modelo de la nueva empresa estatal Aguas y Saneamientos Argentinos S. A. (AySA) supone una serie de continuidades con respecto al mecanismo participativo de gestión implementado por AASA, tal como se desprende del siguiente relato:

[...] con el problema de desempleo generalizado del 2001, 2002, se empezaron a hacer convenios. Te hablo de cuando estaba todavía Aguas Argentinas [...] los convenios eran para que la gente de los barrios carenciados llevara a cabo las redes. Entonces se hizo un tipo de obra que se llamaba mecanismo participativo de gestión. Se hicieron obras en distintos lados, casi todas villas y asentamientos y sirvió como antecedente a lo que posteriormente fue el Plan Agua + trabajo. En el año 2004, teniendo en cuenta la experiencia del mecanismo, el Gobierno nacional decidió la creación de este Plan para un partido en particular. Cuando se crea AySA se generaliza para el resto de los municipios del área de acción de AySA (personal de la empresa, comunicación personal, 8 de septiembre de 2012).

Uno de los puntos de continuidad entre la gestión privada y la pública se refiere al principio por el cual solo la población más vulnerable social y ambientalmente debe hacerse cargo de gran parte de la extensión de las redes de servicios de agua y cloacas en asentamientos y depen-

\footnotetext{
5 El saldo de personas sin provisión de los servicios de agua potable y redes cloacales calculado por Azpiazu para el año 2002 es considerablemente menor al de la empresa $(800.000$ y 1.032.000 respectivamente), aunque de todas maneras confirman el incumplimiento del contrato y la falta de inversiones por parte de AASA.
} 
den de la implementación de dos programas: Agua + trabajo y Cloacas + trabajo. Ambos están vinculados a los recursos de otro programa estatal del Ministerio de Desarrollo Social de la Nación, el Programa de inversión social con trabajo "Argentina trabaja" (en adelante, Argentina trabaja). Este es el último eslabón de los programas de financiamiento público que desde 2003 vienen incentivando la creación de cooperativas para distintos fines. Como en el mecanismo participativo de gestión, las responsabilidades en los programas Agua y Cloacas + trabajo se dividen de forma similar: los municipios seleccionan los barrios, la empresa asegura la factibilidad técnica, aporta materiales, supervisa los trabajos y capacita a la mano de obra; las cooperativas aportan su trabajo a cambio del ingreso correspondiente al programa. Más allá de una mejora relativa en los porcentajes de distribución y extensión de los servicios, la implementación de ambos programas, así como la de Argentina trabaja en su conjunto, ha generado más cambios respecto a los actores locales que al interior de las empresas proveedoras de servicios. Antes de aludir a los cambios acontecidos, sigue una breve descripción del barrio analizado. Me refiero al barrio como Reconquista, por su localización sobre la planicie de inundación del río que lleva ese nombre.

\section{Ubicación y descripción del barrio Reconquista}

Sobre el territorio de la provincia se extiende el río Reconquista, considerado el segundo más contaminado de Argentina (Curutchet, Grinberg y Gutiérrez, 2011; Defensor del Pueblo de la Nación, Ombudsman Nacional, 2007). Sobre la llanura de inundación del tramo inferior, el más contaminado de este río (Curutchet et al., 2011; Defensor del Pueblo de la Nación, Ombudsman Nacional, 2007) y al noroeste de la CABA se asienta el barrio Reconquista. Ocupa cerca de 50 hectáreas de terrenos que originalmente eran bañados y totorales que los propios vecinos fueron rellenando con residuos de distinto tipo a medida que se instalaban. La altura del suelo en Reconquista decrece unos dos metros en dirección sur-norte y culmina hacia el noreste en un arroyo denominado El Zanjón por los habitantes del barrio (Curutchet et al., 2011). En líneas generales, Reconquista reúne todos los componentes característicos de un asentamiento de la periferia de la RMBA —ocupación ilegal de una planicie de inundación, cons- 
trucciones con materiales precarios, pobreza extrema, alta densidad poblacional, vuelcos industriales, descargas cloacales, basurales a cielo abierto $^{6}$ e insuficiente y precaria provisión de servicios básicos- y además su vecindad con el relleno sanitario más grande de la región, denominado Ceamse por los vecinos, en referencia a la empresa que lo gestiona (Curutchet et al., 2011).

Figura 1. Mapa del barrio Reconquista

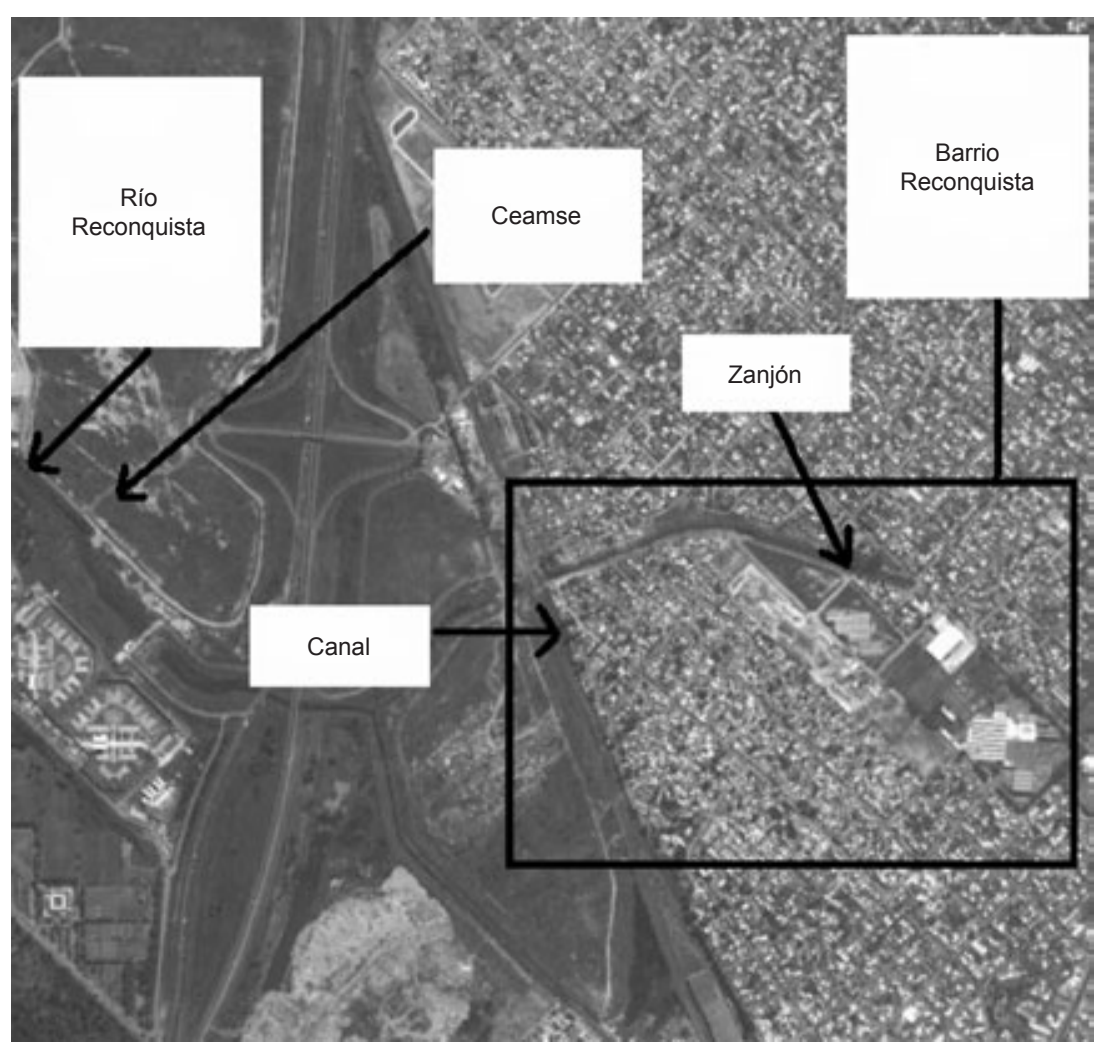

Fuente: elaboración propia con base en imagen de Google Earth.

El crecimiento poblacional del barrio, aunque exponencial, ha estado marcado por dos momentos de crisis económicas nacionales (1989 y

6 Es la denominación coloquial que reciben las disposiciones de residuos ilegales y sin tratamiento. 
2001-2002) y ha definido las características que presenta hasta hoy. Si bien guarda las características propias que definen a los asentamientos, en su interior pueden distinguirse divisiones que se observan tanto física como simbólicamente. La primera marca es el mencionado decrecimiento que sufre la altura del suelo. El punto medio, donde la pendiente sur-norte es más pronunciada, señala el límite entre Bajo y Alto Reconquista. Este suele ser referido por los habitantes del barrio como una marca de distinción entre un lado y otro del barrio. Asimismo, esta división se observa en la lógica de ocupación del barrio que se fue realizando de arriba para abajo. El "fondo" del barrio (Bajo Reconquista) es lo último que se pobló y, según los vecinos, el peor sector, en lo que refiere a las construcciones de las viviendas que lo caracterizan y a los riesgos que lo asechan. Los riesgos referidos por los vecinos aluden a todo aquello que pueda atentar contra su seguridad, tanto para grupos de jóvenes que realizan actividades delictivas allí como para la presencia del Zanjón.

ElZanjón donde culmina el barrio es la segunda marca que distingue a Bajo de Alto Reconquista. La lógica local es la siguiente: “Cuanto más cerca del Zanjón se está, más expuesto a enfermedades" (promotora de salud del barrio, comunicación personal, 5 de abril de 2013). Esto se debe a que el Zanjón suele desbordarse ante cualquier precipitación y a que es, en realidad, parte de un canal que se desprende del río Reconquista, por lo que recibe y arrastra consigo todos los contaminantes que circulan por sus aguas. También es depositario de los vuelcos cloacales del barrio, de desechos industriales y de descargas ilegales de residuos.

En el contexto descrito, la cantidad y calidad de los servicios básicos adquiere una gran importancia. A efectos de describir la situación de los servicios en el barrio, algunas características socioeconómicas de su población y su percepción sobre los principales problemas que aquejan al barrio, correalicé un total de 210 encuestas divididas de la siguiente manera: 113 en Alto Reconquista y 97 en Bajo. En consideración de lo manifestado por los encuestados, como límite geográfico del estudio se utilizó el Zanjón. El criterio para definir la cantidad de encuestas en cada sector dependió de la proporción de habitantes 
de cada uno de ellos. Con excepción de las mencionadas, las encuestas no detectaron otras diferencias importantes entre una y otra parte del barrio. Por ello, las cifras que se presentan a continuación refieren al total de los encuestados.

\section{Acceso a los servicios y consumos energéticos}

Según pudo observarse, el acceso a los servicios de electricidad, recolección de basura y agua corriente es alto: 99\%; 90,4\% y 87,6\%, respectivamente. Entre los vecinos que manifestaron contar con energía eléctrica, solo un $10 \%$ mencionó que contaba con medidor propio. Un $28 \%$ declaró tener tanque de agua y de ellos un $25 \%$ dijo acumular agua. Aun cuando un 1,4\% manifestó contar con el servicio de cloacas, es probable que esa respuesta se deba a la existencia de pozos u otros tipos de cañerías, ya que el área estudiada y los barrios circundantes a Reconquista no poseen ese servicio.

En referencia a lo que señala la bibliografía especializada y las fuentes de datos secundarios sobre asentamientos (Defensor del Pueblo de la Nación, Ombudsman Nacional, 2007), considero importante remarcar que al menos en Reconquista la falta de acceso a los servicios no es el problema, sino más bien la calidad de los mismos.

Por ejemplo, $77 \%$ de los entrevistados señaló que la electricidad se corta con frecuencia. Entre ellos, un $87 \%$ manifestó que los cortes se producen en invierno como mínimo una vez por semana; un $82 \%$ mencionó que los cortes duran más de tres o cuatro horas y 51,5\% que tiene problemas referidos a la caída de tensión frecuentemente. Un 14\% reconoció haber sufrido lesiones relacionadas con las instalaciones eléctricas; los problemas más señalados fueron la conexión general precaria de la zona, la tensión de la energía y, nuevamente, los cortes frecuentes, sobre todo en invierno. Durante los últimos dos años, son conocidos en el barrio al menos cuatro hechos de deceso de personas por accidentes domésticos vinculados a la energía eléctrica.

Por su parte, la basura en todas sus dimensiones ha sido señalada por los vecinos como uno de los principales problemas que aquejan al barrio (figura 2). El sistema de recolección de basura del barrio es 
muy precario y consiste en un par de carretas manejadas por vecinos contratados por la municipalidad, quienes circulan por Reconquista recogiendo los desechos de los habitantes, los cuales van a parar a un contenedor ubicado al costado de una cancha de fútbol, en la entrada al barrio. Un camión de la empresa privada que presta el servicio en el resto del partido recoge la basura del contenedor con frecuencia irregular.

\section{Figura 2. Principales problemas del barrio según los entrevistados}

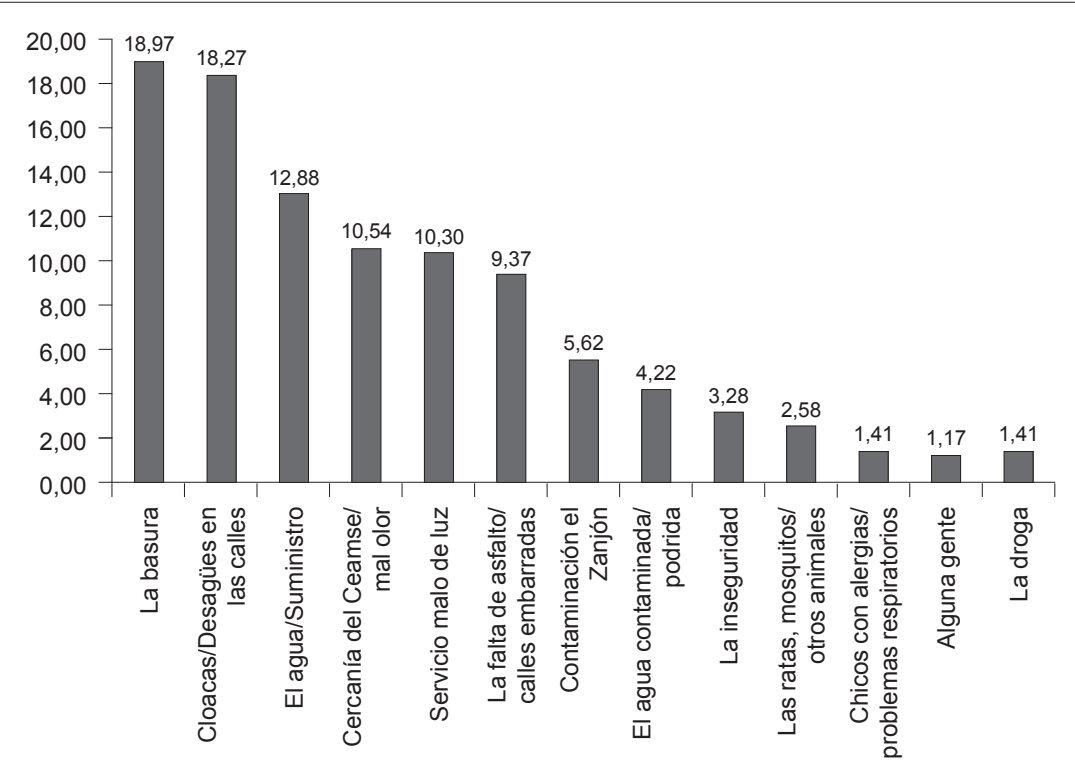

Fuente: elaboración propia en conjunto con el Grupo del Observatorio Ambiental del barrio Reconquista.

Por su parte, el acceso al gas se produce casi exclusivamente mediante garrafas (97,5\%); sin embargo, solo un $43 \%$ compra la garrafa social. ${ }^{7}$ $\mathrm{Al}$ ser consultados por qué no compran la garrafa social, las respuestas aludieron a que no se consigue en la zona. También declararon que la garrafa social dura menos tiempo que la de la principal proveedora del mercado.

\footnotetext{
La garrafa social es un servicio que presta el Estado local a un precio mucho menor al del mercado.
} 
$\mathrm{El}$ acceso al agua corriente sigue las mismas pautas que los anteriores servicios. Es alto —un 88\% de las personas mencionó tener agua de red-, aunque precario y es provisto por la empresa AySA. Solo en unas pocas cuadras del barrio la conexión de las casas a la red de agua fue realizada por la empresa prestataria (por entonces AASA) y las restantes son abastecidas por un frágil sistema de mangueras plásticas que los propios vecinos han tendido. Las mangueras están expuestas a pinchaduras y cortes y suelen cruzar zanjas a cielo abierto, a las cuales son arrojadas las aguas servidas de las casas (Curutchet et al., 2011). Quizá por ello un porcentaje importante de los entrevistados desconfía de su salubridad. Por ejemplo, un 41 \% comentó que compra botellones de agua para consumo humano; un $66 \%$ de este último manifestó comprar entre dos y cuatro botellones de diez litros de agua por mes. Como señalan parcialmente los resultados de la encuesta, en todos los casos se trata de un tipo de acceso precario y basado en la iniciativa de los vecinos del barrio. Como ya he dicho, ciertos líderes locales adquieren una importancia mayor. A continuación relato la historia de uno de ellos: León.

\section{Muerto el general Perón, viva el rey León}

Durante las décadas del ochenta y del noventa, individuos como los líderes locales y organizaciones como las unidades básicas ocupaban lugares centrales dentro de las redes de resolución de problemas del clientelismo peronista (Auyero, 2001). Utilizo el término "centrales" para referirme a dos aspectos. Por un lado, los líderes y las unidades básicas lo eran porque se encontraban entre los clientes y los patrones políticos y, por otro lado, porque eran los medios de comunicación más directos entre el barrio y el Estado. De ese modo, los líderes locales y las unidades básicas servían a la captura política de los clientes por los patrones políticos y a la solución de problemas cotidianos de los primeros mediante la distribución de recursos materiales y simbólicos facilitados por los segundos (Auyero, 2001). De 2003 en adelante, la profusión de programas de financiamiento público ha transformado las viejas organizaciones locales y fomentado la generación de unas nuevas, con lo que desplazaron de su lugar de privilegio a las unidades básicas. Dicho desplazamiento no implicó la desaparición de los líderes locales; el panorama actual parece ser mucho más complejo que eso. 
Durante el trabajo etnográfico, encontré novedosas organizaciones que auspiciaron otros liderazgos. Las formas en las que el Estado y las nuevas organizaciones actúan e interactúan por obra y gracia de los programas de financiamiento mencionados han afectado a los viejos líderes locales. Algunos de ellos tal vez han perdido su influencia, pero otros se han transformado en los principales referentes de esas organizaciones y otros tantos continúan siendo referentes del barrio aun cuando ya no respondan a un patrón político ni intercambien favores por votos. En todos los casos, lo que los distingue de otras formas de participación política local y a su vez los iguala entre sí, es la persistencia de dos de sus atributos primordiales: su profundo conocimiento de la geografía e historia del lugar y de la historia y las necesidades de sus habitantes así como su habilidad para transferir recursos concretos del Estado, del partido o de una empresa prestadora de servicios para solucionar problemas concretos que aquejan al barrio o a uno o más de sus habitantes. León es el referente más mencionado y reconocido por los vecinos como un "reparador de problemas".

Cuando uno camina por el barrio con León, parece casi imposible avanzar más de cinco metros sin que lo detenga algún vecino para saludarlo o conversar con él. Parece conocerlos a todos y todos, desde los más pequeños hasta los más ancianos, parecen conocerlo a él. En muchas ocasiones les hace preguntas sobre alguna situación particular que les compete o sobre la situación de algún familiar cercano. En otras, los vecinos que lo detienen requieren su ayuda para la resolución de algún problema. Quizá por esta popularidad de la que goza, el propio León se compara a sí mismo con la figura del intendente:

Pancho: Lorena, anotá el número de León para los focos.

Lorena: Sí, ahora anoto.

León: Pero che... iya parezco el intendente yo! ¡Yo no soy el intendente!

Lorena: No, no es el intendente, pero usted es más que el intendente acá. Usted es más que el intendente, porque es la realidad. Porque cuando falta la luz, primero vamos donde León y él es el que contacta a la empresa.

León: Falta agua acá, que hay un quilombo. 
Lorena: También lo vamos a buscar a usted, sin usted ni se animan a venir los de AySA.

León: Bueno, ¿cuántos focos son? ¿Dos o tres?

Pancho: Tres.

León: Bueno. ¡Pero faltan unos cuantos más che! No, no. ¡Vamos a poner para todo el barrio y ya!

Durante los primeros años de la década del noventa, el barrio no paraba de crecer y poblarse. Por entonces, León poseía todas las características típicas de un puntero peronista. Muy ligado al intendente Semino $^{8}$ (quien gobernó el distrito durante casi toda la década) su lealtad y respeto hacia él eran, según su testimonio, inquebrantables:

Yo siempre apoyé a Semino, siempre trabajé para él. Siempre lo apoyé porque él era un hombre que se ganó el respeto de nuestro movimiento [el Partido Peronista], él siempre hizo mucho por la gente y yo lo ayudé cuanto pude.

La historia de León en Reconquista precede a la de Semino al frente del Gobierno local. En ninguno de los testimonios recabados queda claro si la relación entre ambos era previa a la asunción de Semino como intendente o si se inauguró allí. Lo cierto es que León desempeñó por aquellos años un papel fundamental en la provisión de agua potable, en gran parte gracias al apoyo de Semino. Y aquel parece el punto donde Semino comienza a tomar valor en el relato de León:

Al principio a mí me apoyaron de la provincia... Arreglamos una reunión en el barrio y una vez que conseguí que me hicieran una propuesta me hice cargo de representarlo en su totalidad [...] aquello era difícil, porque era un asunto provincial como municipal y al principio el Gobierno municipal no era peronista, pero a mí lo único que me importaba era el agua. Entonces, gracias a esa propuesta, pude conseguir materiales, un montón de materiales que me conseguían de la provincia. Pero las cosas se pararon por

8 Todos los nombres son ficticios con el fin de preservar la identidad de los entrevistados 
un tiempo, hasta que asumió el intendente Semino. Entonces ahí sí estábamos todos del mismo lugar. Igual yo pensé que iba a haber otro problema: que la empresa ya era privada [se refiere a AASA]. Pero al final hicimos con Semino y la empresa un acuerdo formal y lo logramos; eso fue en el 1993 [...] fue un trabajo extraordinario y no lo hubiese logrado sin Semino.

León logró que AASA instalara la cañería central que hoy abastece de agua a casi todo el barrio. Según lo recuerda, fue él mismo quien contactó agentes de la empresa proveedora y los condujo al barrio para que le dijeran si era factible hacer lo que él pretendía. Y más tarde, también fue León quien se encargó de organizar a los vecinos en una cuadrilla de trabajo para hacer las labores necesarias con el fin de que la empresa pusiera la cañería:

Cinthia: ¿Y cómo hicieron el trabajo?

León: Y... empecé a caminar cuadra por cuadra y a hablar con los vecinos. "Mañana necesito que caves toda la cuadra de tu casa", les decía "y entonces después vengo con los trabajadores de la empresa a instalar la cañería". Pero al principio fue difícil, porque no tenía nada más que ofrecerle a la gente. Entonces conseguimos algunos fondos del municipio para pagarle a veinte tipos para que hicieran el trabajo. Se suponía que íbamos a empezar en febrero. Hacía mucho calor ese día. Empezamos un viernes. Nadie trabajó el sábado y el domingo, porque era fin de semana y los de AASA venían el lunes. Ese mismo día vinieron los muchachos a decirme: "León, no vamos trabajar hoy porque queremos que nos paguen antes”. ¿Qué podía hacer? Llamo al municipio y me dicen que el dinero no va a estar para ese día y si los de AASA se iban, quién sabe cuándo podíamos hacerlos volver. ¡Esto era algo para todo el barrio! ¡No importaba si eran del Partido o no! ¡Tampoco era para alguien de afuera! Así que fui de vuelta a hablar con los vecinos para pedirles ayuda. Y me acuerdo que un viejito de 80 años me dijo: "León, yo lo hago aunque me tenga que morir haciéndolo". Y finalmente se nos unieron un montón de vecinos, sin pagarles un peso y lo hicimos. No era fácil, pero yo lo hice más fácil. 
Las referencias personales de León sobre todo lo hecho abundan en sus relatos: "Yo hice, yo fui, yo lo gestioné". En un primer momento esto puede parecer una exageración de su parte y quizá así lo sea. Por ese motivo, para algunos vecinos su figura no despierta mucha simpatía. No obstante, incluso estos últimos lo reconocen como un personaje importante en la historia del barrio:

Rafo: Vos donde lo encontrás a León siempre te dice "yo hice", "yo hice"; siempre quiere figurar y nosotros ya sabemos cómo es el tema. Pero bueno, lo que él hizo fue una cosa muy linda para el barrio y eso no se lo podemos discutir. Tener agua es muy importante. Creo que nadie lo hubiese podido lograr aparte de él.

No parece un hecho menor que, tras veinte años de haber logrado la provisión de agua (entre otras cosas), el reconocimiento hacia León esté, en la mayoría de los casos, relacionado con la provisión de servicios para toda la comunidad. Aún hoy, con la profusión de organizaciones dedicadas a la prestación de servicios y sin patrón político al cual responder, León continúa siendo una referencia cuando surge algún problema con la prestación de los servicios de agua y luz. En dos ocasiones he presenciado cómo León se apersonaba en el barrio con trabajadores de la empresa de energía eléctrica para solucionar algún inconveniente. Lo mismo sucedió con AySA en repetidas ocasiones. Así lo cuentan León y una vecina:

León: no sé qué trabajo hicieron con el agua; qué cagada hicieron... el tipo yo sé que metió un caño, un... clavó un...

Pao: un fierro y se rompió el caño principal.

Patricio: ¿qué pasó?

León: no, ayer... vos estuviste en el... en la cañería de agua, el cruce, el caño maestro rompió... Metió un fierro no sé para qué. Pao: sí, reventó un caño.

León: jah, ah! Milagro que quieren hacer algo y hacen cagada. Patricio: ¿y ahora?

León: no, ya vinieron... ya lo arreglé yo. Y porque es lo que digo yo, no es sencillo... porque acá, vos le decís a la empresa, llegan 
hasta la entrada del barrio, se dan la vuelta y se van. No sé la luz, ¿Qué pasa con la luz?

Lucas: y sí, es verdad.... Si acá no van y le dicen a León, nadie tiene luz... Así que vamos y lo buscamos a él, "anda a buscar a León” todo León, todo León.

León: no porque... yo se lo hice, porque es un tema... porque si yo no estoy y vienen los muchachos, ¿qué pasa? Se van.

Sin embargo, ahora que León no responde a ningún patrón político, resta preguntarse qué será de él en los próximos años. ¿Podrá hoy impulsar obras como las que llevó a cabo entonces? Tal como él lo recuerda, todos sus grandes logros, como la provisión de agua y la construcción de una escuela pública localizada en el interior del barrio, se remontan a su colaboración con el exintendente Semino:

León: yo lo apoyé a Semino, yo trabajé mucho y lo apoyé... se mandó un par de macanas porque... lo traicionaron primeramente, lo traicionaron... pero él también me apoyó, logramos muchas cosas...

Patricio: ¿la escuela de cuándo es?

León: de allá, de esa época. Claro, si él me dio una mano para comprar las tierras... No, en eso... estuvo presente en la primera etapa. En el agua corriente también me ayudó mucho... yo con él, inauguramos la primera etapa con él, vinieron todos los canales de televisión... y yo le dije: “¿Para qué quiero la televisión? Yo quiero el agua".

Parece muy pronto aún para arribar a conclusiones que respondan a las preguntas anteriores. La profusión de nuevas organizaciones ha perturbado las formas en que los líderes locales actúan y se organizan. A los fines del presente, parece tan importante como aquello comprender la manera en que dicha profusión continuará afectando la relación entre el Estado y la población más pobre y los modos como son y serán provistos los servicios básicos. Sin la pretensión de contestar este cuestionamiento o los anteriores, pero con ellos como guía, sigue a continuación una descripción de la profusión de la vida organizacional en Reconquista. 


\section{"Una nueva forma de hacer política": la profusión de la vida organizacional}

Desde el retorno de la democracia hasta 2003, entre las organizaciones populares de los asentamientos, las unidades básicas fueron las que ocuparon un lugar privilegiado. Con base en estas organizaciones, los líderes locales peronistas resolvían problemas concretos que afectaban a uno o más vecinos del barrio, a la vez que competían entre sí por el apoyo político de aquellos. El relato que tiene a León como protagonista no es más que una muestra de ello. Tan cierto es que León ha sido el referente más mencionado como lo es el hecho de que tuvo que competir, incluso durante su tiempo de esplendor, con otros líderes también señalados por vecinos del barrio:

Carlitos: y los Rosas eran muy fuertes en el barrio trabajando políticamente. No sé con quién trabajaban, pero eran muy fuertes... Abel: ¿te acordás acá en el barrio cuando eran los referentes? estaba León, el Tumba y Pepino y vos, donde los encontrás, ellos siempre dicen "yo hice" y después lo encontrás al otro y te dice "yo hice". Esa es la pelea históricamente acá, digamos.

Lucho: A mí, el más importante me parece que era el Pitufo [...] tenía la unidad básica de la calle Marsés y era muy amigo de un concejal.

El conjunto de las referencias son formuladas en tiempo pasado. Ello se debe a que, si bien el peronismo continúa siendo la identidad política más extendida en los barrios como Reconquista, en la última década, el advenimiento de nuevos programas de financiamiento público ha desplazado de su lugar de privilegio a las viejas unidades básicas (y con ello a algunos de los viejos líderes locales peronistas). Como resultado de estos mismos programas, su lugar ha sido ocupado por una red más variada de organizaciones populares dedicadas a proveer todo tipo de servicios (Collier y Handlin, 2009). En algunos casos, la creación de "nuevas" organizaciones (a veces identificadas como ONG por observadores y participantes) ha sido acompañada por el surgimiento de nuevos líderes y, en otros, ha servido a los viejos líderes como una herramienta para perpetuar su liderazgo. Así lo expresa, 
con cierto cinismo, un viejo líder peronista devenido director de una de estas organizaciones:

Tumba: no, ahora es algo que lo arman ellos, para decir "desde el punto de vista institucional tenemos esto". Es lo mismo que nosotros. Hoy todas las unidades básicas son ONG. ¿Por qué? Porque se veía un cambio en una nueva forma de hacer política.

Además de las unidades básicas, otro tipo de organizaciones populares se vieron afectadas por esta "nueva forma de hacer política". La literatura sobre clientelismo no las incluye dentro de su objeto de estudio, porque en general no eran organizaciones partidarias o no participaban del proceso de compra de votos. En este caso me refiero a un conjunto variado de organizaciones populares locales ligadas a tareas de asistencia social: comedores, guarderías, merenderos, apoyo escolar y microemprendimientos sociales, entre otros. Según el relato de varios vecinos, la creación de dichas organizaciones coincide con dos momentos: las crisis socioeconómicas y políticas de 1989 y de 2001-2002, episodios que además impulsaron el crecimiento de la población en el área. Antes de señalar un tercer momento de creación de organizaciones, veamos cómo el papel de la crisis de 1989 es explicitado en la historia “oficial” de una red (Red Gesol) que incluye organizaciones del barrio en estudio:

La Red de Organizaciones de Gestión Solidaria RED GESOL nació en el año 1989 en el contexto de la hiperinflación, el cierre masivo de fábricas y el inicio del proceso de reestructuración del Estado y las privatizaciones con el objetivo de dar respuesta a la desocupación desde la propia comunidad afectada. Su primera forma jurídica se concretó tres años después con la fundación de la Asociación Mutual de Empleo y Gestión Solidarias, cuya misión fue y sigue siendo generar ingresos dignos a través de formas de autoempleo, microempresas y empresas sociales en el marco de la Economía Social y el Desarrollo Local. Durante la década del 90, además del Derecho al Trabajo Decente y a medida que la situación socioeconómica se agravaba para los sectores populares, en la RED GESOL, fue cobrando importancia la concreción de 
otros derechos básicos (alimentación, viviendas, salud, educación, cultura, recreación). Hoy, conforman la RED GESOL más de 60 organizaciones con distintos grados de institucionalidad y tipos organizativos: desde centros de promoción comunitarios barriales hasta entidades de desarrollo integradas por técnicos y profesionales. Está estructurada con visión federal en regiones como NOA, NEA, CENTRO y RMBA (Red Gesol, 2014, p. 1).

Para estas organizaciones, el autoempleo, la microempresa o la empresa social son modos de responder ante una situación de crisis en la que los derechos básicos son puestos en cuestión. Según el líder de una organización de Reconquista, igual rol parece haber cumplido la crisis de 2001-2002:

Petrosa: la asociación se creó un año y medio antes de empezar acá, creo en el 2001-2002, después de la debacle de De la Rúa. ${ }^{9}$ Ese año, nosotros hicimos un corso ${ }^{10}$ para fundar un comedor y a través de eso nosotros hicimos una asociación civil para poder seguir manteniéndolo con subsidios de la provincia.

En estas organizaciones, varios autores han visto el germen del fenómeno piquetero (Gómez, 2006; Pereyra et al., 2008; Svampa y Pereyra, 2003), sobre todo en aquellas relacionadas con el segundo momento. Su trayectoria posterior al estallido de dicho fenómeno también ha sido documentada, aunque con menos entusiasmo. Los autores que sí continuaron analizando el fenómeno han dado cuenta de la incorporación de las organizaciones a la estructura del Estado, mediante su inclusión en la esfera pública como beneficiarios de los programas de financiamiento público - proceso que han denominado como burocratización de las organizaciones piqueteras (Natalucci, 2010; Perelmitter, 2012)—. Aun en estos casos pareciera no haberse llamado suficientemente la atención sobre un aspecto que en mi trabajo

\footnotetext{
9 Presidente de Argentina durante el período 1999-2001. Debió renunciar a su cargo ante la profunda crisis de entonces.

10 Desfile con trajes festivos y música de ascendencia afroamericana, muy popular en las provincias del Río de La Plata.
} 
de campo se ha mostrado muy relevante: el aumento cuantitativo de organizaciones populares como resultado de la profusión de los programas de financiamiento público. Ya sea mediante la transformación de viejas organizaciones —incluidas muchas unidades básicas- o por medio de la creación de nuevas organizaciones populares, el aumento de organizaciones en el barrio Reconquista ha sido cercano a un 300\% (figura 3). Según el testimonio de vecinos y líderes locales, antes de la profusión de programas las organizaciones eran unas seis y hoy alcanzan, al menos, dieciocho. Se puede pensar este aumento como un tercer momento de creación de organizaciones populares, cuyo punto de inicio data de 2003 y se acentúa por razones políticas tras las elecciones legislativas del año 2009 (Zarazaga, 2013).

A la hora de analizar la influencia de los programas de financiamiento público que caracterizan al momento anterior, me parece importante señalar las continuidades y los cambios sufridos por el conjunto de los actores locales y por las maneras como se relacionan con el Estado, tanto para los actores señalados por la literatura del clientelismo como aquellos ponderados por la literatura piquetera. En este apartado, del programa que más me ocuparé es del mencionado Argentina trabaja. Tiene asociados con sus recursos a otros dos programas específicos que también ya he mencionado: Agua + trabajo y Cloacas + trabajo. En líneas generales, Argentina trabaja es un programa que fomenta la creación de "cooperativas" compuestas por un máximo de treinta personas a cargo de un responsable (también cooperativista). Las cooperativas realizan una serie de labores relacionadas con la prestación de servicios, a cambio de un estipendio mensual.

En la práctica, algunas de las cooperativas creadas nacen como apéndices o derivaciones de las organizaciones populares surgidas en los momentos previos, consagradas a tareas vinculadas con la asistencia social u organizaciones partidarias del tipo de las unidades básicas. En cambio, otras son obra de la difusión de los programas estatales. Este fenómeno se enmarca en esa "nueva forma de hacer política" a la que se refería el Tumba, que he denominado la nueva política de los pobres, donde el Estado se muestra casi omnipresente, aunque no para asegurar la satisfacción de las necesidades básicas, sino para 


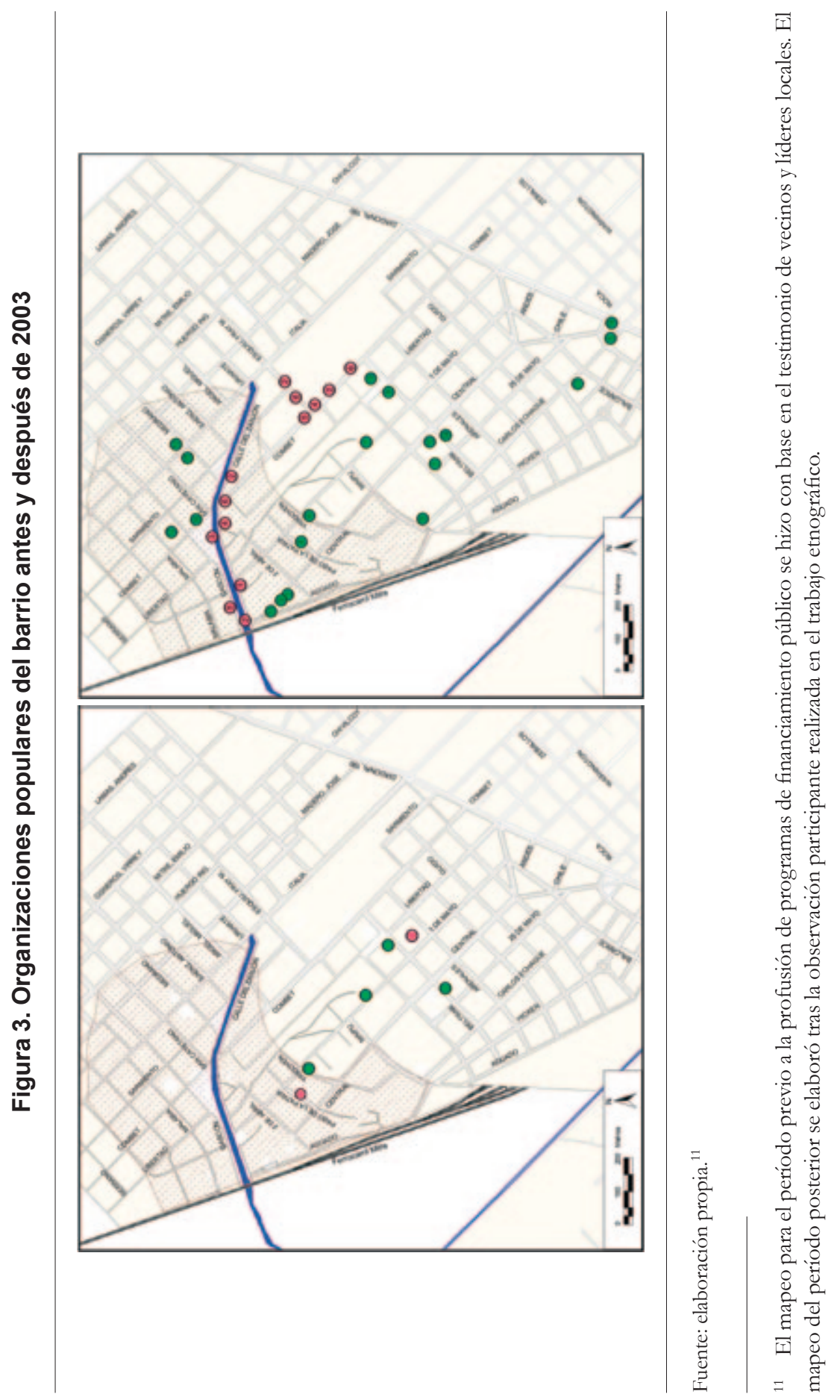


incorporarlos en su estructura y promover el asociativismo entre los pobres (cada vez en mayor cantidad) para que ellos, con el apoyo del financiamiento público, resuelvan sus propias necesidades. Pero allí no acaban los cambios. Con base en el trabajo de campo, otros aspectos importantes pueden señalarse de esta nueva política. Por ejemplo, el aumento cuantitativo de individuos que conforman las organizaciones. En Reconquista, del total de los vecinos encuestados, un 45\% declaró ser beneficiario de al menos uno de los programas de financiamiento público y $31 \%$ declaró serlo de Argentina trabaja. En otras palabras, ese $31 \%$ reconoció formar parte de una cooperativa de trabajo.

No es de extrañar, entonces, que al caminar por la calles de Reconquista resulte casi inevitable toparse con cooperativistas en pleno desarrollo de sus tareas. Tampoco es un dato menor que las tareas que llevan a cabo estas cooperativas estén relacionadas con la provisión de servicios casi en todos los casos. Las dificultades que deben afrontar para ello los cooperativistas no son menores: falta de materiales, de conocimiento, de vestimenta para realizar la labor, de coordinación con áreas de Gobierno, etc. Esto puede atribuirse a la forma de "socio" que adquiere el Estado en este tipo de barrios: un Estado presente en cada programa y cooperativista, pero que, en vez de asegurar la prestación de servicios básicos, otorga a las cooperativas de vecinos los elementos mínimos para que ellos mismos se hagan cargo. Ya he mencionado en otro apartado el caso de la recolección de residuos. Otros eventos también pueden ayudar a entender mejor cómo funciona el Estado en estos contextos. Por ejemplo, en vez de remediar la contaminación de los arroyos del barrio, como correspondería según ley, el Estado subsidia a una cooperativa de vecinos para que "limpie" los arroyos, sin otorgarles para ello los mínimos implementos de seguridad. Al respecto veamos el testimonio de Lilly, quien enumera algunas de las dificultades que las cooperativas deben sortear a causa del accionar del Estado:

Lilly: Nosotros somos los que tratamos de limpiar el Zanjón; tratamos, porque la verdad que no se puede hacer bien [...]. Nosotros pedimos volquetes y si se les canta al corralón te lo traen y lo ponemos adentro del volquete y se los llevan... pero a veces te 
dicen "sí, te voy a bajar volquete". Ellos te tienen que bajar todos los días el volquete y a veces no te lo traen.

Algo similar sucede con la implementación del mencionado programa Agua + trabajo. A continuación, Rial, el responsable de una de las cooperativas encargada de llevarlo a cabo en Reconquista, se queja de los materiales con los que tienen que trabajar, de la falta de preparación del resto de los cooperativistas y hasta de la falta de información básica que la empresa debería tener sobre el territorio del barrio:

Rial: y esto es un trabajo de hormiga, porque primero le tenés que enseñar a los muchachos. Los muchachos son todos laburantes, ${ }^{12}$ pero los únicos que sabemos de esto somos yo y Carlos (que es aquel).

Patricio: ¿pero no tienen como una especie de capacitación? Rial: sí, los talleres. Pero no sirven para nada [...] son como seis meses, ¿no? Una vez por semana y después resulta que son tres talleres, dos horas ¿Cuánto podés aprender? [...]. ¡Para colmo mirá los picos que nos dan! $!^{13}$ Este es piso de relleno, todo escombros, todo piedra, esto no podés hacerlo a mano [...]. Yo se los dije: "Con esto vamos a estar toda la vida", hace falta una electroexcavadora para hacer esto, ¿me entendés? Y ahí sí, lo tienen que venir a hacer ellos o capacitarnos a todos [...]. ¡Mirá la otra, mirá la otra! La otra es el mapa [...] fijate vos que sos de la universidad, pero yo no, yo soy bruto y hasta yo y cualquier vecino se da cuenta que esto no tiene nada que ver con el barrio ¡Mirá! ¡Mirá acá! Te lo ponen como si esto fuera todavía el río, ¿نes?

Patricio: ¿lo habrán sacado del Catastro Municipal?

Rial: ¡claro que sí! Y como estas tierras no son legales, figura como si todavía fuese agua... ¡A vos te parece! ¿Te parece que se puede trabajar bien así? Se hace lo que se puede.

Es importante señalar que, aunque sea con intermitencias y de forma precaria, las cooperativas como prestadoras de servicios suelen llevar

12 Expresión popular derivada del lunfardo ítalo-argentino que significa "trabajadores".

13 Herramientas que se utilizan para realizar los pozos donde luego se instalan cañerías. 
a término sus labores. Como han señalado algunos autores (Zarazaga, 2013), esta confluencia, contradictoria quizá, de una lógica clientelar en la repartición del financiamiento con labores ligadas a la provisión de servicios que satisfacen al conjunto de la comunidad parece componer las características más sobresalientes de esta nueva política de los pobres. El testimonio de una compañera de Lilly en la limpieza del Zanjón señala de un modo concreto ambos aspectos:

Mary: ahora, lo que más nos preocupa es el contrato. Ahora en junio tendríamos que ver si nos extienden el contrato para dos años más, que estamos esperando que nos den, porque el trabajo que nosotros hacemos nadie lo hace, ¿eh? Nos metemos ahí adentro del Zanjón, sacamos todas las bolsas que hay adentro, sino quedaría todo tapado. Esto ahí, si venías hace un rato estaba alto, porque estaba todo tapado [...]. No, pero al menos para que vean que nosotros hacemos el trabajo, ven de afuera... porque después tenemos que renovar y el que firma no nos quiere firmar porque dice: "Ustedes tienen muchas denuncias de que no hacen el trabajo" y en realidad él no nos quiere firmar porque nosotros pertenecemos a la BP (nombre de la organización) y como hay conflicto ahí y como ellos quieren tirar a favor de ellos, entonces no nos quieren renovar por eso $[\ldots]$ y siempre le presentamos los materiales, así fotos, videos, gente que pasó por acá haciendo entrevistas y todo eso... Pasaron mucha gente, entonces nosotros le mostramos para que nos firme, no es que queremos que nos firme y nos quedamos en casa; no venimos cuando llueve porque es peligroso, pero nosotros venimos siempre. No porque seamos de BP nos van a dejar afuera... acá hay mucha gente grande que no puede hacer otros trabajos; hay compañeras con distintas enfermedades que en otros trabajos no los toman. Solo en las cooperativas pueden trabajar.

Las necesidades de los cooperativistas y las del barrio, la presencia del Estado en un modo particular y las formas que adquiere la organización popular son algunos de los aspectos que se conjugan en este proceso en marcha. Muchas reflexiones pueden derivarse del conjunto de los relatos; con todo, ninguna de ellas es concluyente. De todos 
modos, en el apartado final trataré deresponder algunas de las preguntas planteadas hasta aquí y de señalar las características que hacen de esta, una nueva política de los pobres.

\section{Reflexiones finales}

Al comienzo del presente artículo me propuse, como primer objetivo, señalar la importancia que los viejos líderes locales fueron adquiriendo durante la década del noventa en la prestación de servicios básicos en asentamientos. Como segundo objetivo, quise explorar los cambios sufridos por los viejos líderes y las organizaciones populares y analizar el surgimiento de nuevos líderes y organizaciones, a raíz de la profusión de programas de financiamiento público durante la última década. Al proceso que incluyó dichos cambios lo denominé nueva política de los pobres.

Para comprender en qué consiste esta nueva política, fue necesario repasar las características de aquello a lo que sigue y de lo que se diferencia, en este caso, la "vieja" política de los pobres (Auyero, 2001). La literatura sobre la política de los pobres en Argentina, como en otros lugares del mundo, se ha dedicado en gran parte al estudio del clientelismo. Con independencia del enfoque desde donde se lo trate, en todos los casos este supone una serie de relaciones beneficiosas para los tres tipos de actores que lo conforman: el patrón político, el puntero y los clientes. El papel del puntero es mediar entre el patrón y el cliente, de modo que cada uno de los tres obtenga su beneficio. ${ }^{14}$ Un supuesto de suma importancia para dicho esquema conceptual es el que marca que el puntero posee un amplio conocimiento sobre las necesidades de sus clientes, dado que los favores del primero hacia los últimos son siempre de carácter individual. Aunque en mi trabajo he observado que los punteros cuentan con dicho conocimiento, también he señalado que uno de ellos ha construido su figura, prestigio

\footnotetext{
14 En términos conceptuales, el beneficio que consigue el patrón es la obtención de votos o, de un modo más general, la obtención de apoyo político. El puntero, en tanto mediador entre el patrón y el cliente, recibe distintos beneficios de ambos: puestos de trabajo público y mayores ingresos de parte del primero; lealtad y prestigio por parte del segundo. El cliente adquiere recursos materiales y/o simbólicos que no podría lograr (o podría, pero con mayores costos) sin la mediación del puntero.
} 
y ascendencia en el barrio del que procede, por ser pieza clave en la prestación de servicios básicos que benefician a toda la comunidad y no solo a sus clientes. Considero que este no es un caso aislado; de hecho, en el mismo barrio otras figuras fueron mencionadas. Un primer aporte del presente trabajo es el cambio de denominación de estos sujetos. Los he llamado líderes locales, puesto que exceden el concepto de punteros.

En la literatura sobre clientelismo que se refiere al caso argentino, existe un extendido acuerdo de que el peronismo es el partido clientelar por excelencia. Dentro del comúnmente denominado "aparato peronista", ${ }^{15}$ la figura de la unidad básica ha ocupado un lugar privilegiado como organización popular, sobre todo en el contexto de los asentamientos de la periferia de la RMBA. Sin embargo, con el advenimiento de la nueva política de los pobres, las unidades básicas han desaparecido. En su lugar, ha surgido un conjunto más variado de organizaciones populares, en muchos casos previamente ligadas a tareas de asistencia social (cooperativas, comedores, guarderías, merenderos, apoyo escolar y microemprendimientos sociales, entre otros).

Desde la crisis que atravesara el país durante los años 2001-2002, la literatura respecto al fenómeno piquetero se ha ocupado de estas organizaciones. En un primer momento, las analizó desde la perspectiva de la política contenciosa (Gómez, 2006; Pereyra et al., 2008; Svampa y Pereyra, 2003) y luego examinó el proceso de su incorporación a la estructura del Estado, bajo la etiqueta de "burocratización de las organizaciones piqueteras” (Natalucci, 2010; Perelmitter, 2012). Empero, esta literatura, al igual que la anterior, no se ha ocupado de observar el papel de las organizaciones populares en la prestación de servicios básicos.

Ninguna de las dos parece haber explorado cómo la profusión de programas de financiamiento público contribuyó a mezclar e imbricar los procesos que cada una estudia (burocratización de las organizaciones y

\footnotetext{
15 Con referencia al aparato del clientelismo peronista.
} 
clientelismo); mucho menos parecieran haber percibido otros cambios que he observado en el barrio Reconquista, como el aumento cuantitativo de las organizaciones populares o el incremento en la cantidad de individuos que las conforman.

Aunque no ha sido más que un objeto marginal a lo largo del trabajo, me resta señalar que algunos de los cambios precedentes pueden ser profundizados en relación con el análisis del Estado. En el caso particular de Reconquista, como contraparte del aumento de organizaciones populares, pude observar una mayor presencia institucional, aunque no como garante de la provisión de servicios básicos, sino como socia y financista de los propios vecinos.

En síntesis, según lo observado, son al menos cuatro los rasgos que distinguirían a la nueva política de los pobres frente a la "vieja": 1) el aumento cuantitativo de organizaciones populares y de los individuos que las conforman; 2) el rol predominante de una diversidad de organizaciones populares locales, en reemplazo de las antiguas unidades básicas; 3) la prestación de servicios básicos como una actividad que compete a los líderes locales y a las organizaciones populares, y 4) una mayor presencia institucional del Estado como socio y financista de las organizaciones.

Pese a que lo precedente debe ser tomado con la precaución debida por ser un estudio de caso único, de algo no me caben dudas: la política de los pobres es un proceso en marcha, factible de muchos cambios, avances y retrocesos y es campo fértil para otros tantos exámenes que traten de dar cuenta cabal de sus características.

¿Cómo se relaciona el Estado con los más pobres? ¿De qué formas participan políticamente los más pobres? ¿Cómo se implementan las políticas tendientes a reducir las desigualdades? ¿Cuáles son los derechos y servicios que garantiza el Estado? ¿Cómo lo hace? Son algunas de las tantas preguntas que considero debemos hacernos una y otra vez aquellos que soñamos y abogamos por una sociedad más justa. 


\section{Referencias bibliográficas}

Agua y Saneamientos Argentinos S. A. (2006). Plan de Saneamiento 2007-2020. Buenos Aires: Agua y Saneamientos Argentinos S. A.

Auyero, J. (2001). La politica de los pobres: las prácticas clientelistas del peronismo. Buenos Aires: Manantial.

Azpiazu, D. (2010). Privatización del agua y el saneamiento en Argentina: El caso paradigmático de Aguas Argentinas S. A. Vertigo, (7). Recuperado de http://vertigo.revues.org/9730

Azpiazu, D., y Bonofiglio, N. (2007). Nuevos y viejos actores en los servicios públicos. Transferencias de capital en los sectores de agua potable y saneamiento $y$ en distribución de energía eléctrica en la post-convertibilidad. Buenos Aires: Flacso.

Besana, P. B., Grinberg, S., y Gutiérrez, R. A. (septiembre-octubre, 2011). Construyendo derecho en la periferia urbana: capacidad local, liderazgo político y servicios urbanos en un barrio de la Región Metropolitana de Buenos Aires. Conferencia presentada en el IV Seminario internacional Políticas de la Memoria "Ampliación del campo de los derechos humanos. Memoria y perspectivas". Buenos Aires, Centro Cultural de la Memoria Haroldo Conti.

Brusco, V., Nazareno, M., y Stokes, S. (2004). Vote Buying in Argentina. Latin American Research Review, 39 (2), 66-88.

Catenazzi, A. (2007). Universalidad de las redes de agua y fragmentación urbana en el conurbano bonaerense. Una lectura bajo el prisma de la concesión. En A. Catenazzi, A. Quintar, M. C. Cravino, N. Da Representacao y A. Novick (eds.), El retorno de lo político a la cuestión urbana (pp. 33-56). Buenos Aires: Prometeo Libros.

Ciccollela, P. (2009). Buenos Aires: una metrópolis postsocial en el contexto de la economía global. En P. Pírez (ed.), Buenos Aires, la formación del presente (pp. 35-62). Quito: Olachi.

Collier, R., y Handlin, S. (2009). Reorganizing Popular Politics: Participation and the New Interest Regime in Latin America. Pennsylvania: The Pennsylvania State University Press.

Cravino, M. C., Del Río, J., y Duarte, J. (2007). Magnitud y crecimiento de las villas y asentamientos en el Área Metropolitana de Buenos Aires en los últimos 25 años. Buenos Aires: Universidad Nacional de General Sarmiento. 
Curutchet, G., Grinberg, S., y Gutiérrez, R. (2011). Entre la vida del barrio y la potencia del zanjón: condiciones, fatalismos y posibilidades de la remediación ambiental. Actas E-ICES, (6). Buenos Aires: CNEA.

Defensor del Pueblo de la Nación, Ombudsman Nacional. (2007). Informe especial cuenca del río Reconquista. Primera parte. Buenos Aires: Defensoría del Pueblo de la Nación.

Díaz Langou, G. (2012). La implementación de la Asignación Universal por Hijo en ámbitos subnacionales. Buenos Aires: Cippec.

Fundación Konrad Adenauer. (2007). Pobreza, desigualdad de oportunidades y políticas públicas en América Latina. Buenos Aires: Fundación Konrad Adenauer.

Gerchunof, P., y Casanovas, G. (1995). Privatizaciones en un contexto de emergencia. Económica. Desarrollo Económico, 34 (136), 483-512.

Gómez, M. (2006). Crisis y recomposición de la respuesta estatal a la acción colectiva desafiante en la Argentina (1989-2004). Revista Argentina de Sociología, 4 (6), 88-128.

Grupo del Observatorio Ambiental del Barrio Reconquista (2011). Informe sobre consumo energético. Buenos Aires: Universidad Nacional de San Martín.

Gutiérrez, R. A. (2012) Federalismo y políticas ambientales en la Región Metropolitana de Buenos Aires, Argentina. EURE, 38 (114), 147-171.

Bolay, J. C., Pedrazzini, Y., y Da Cunha, A. (eds.) (1996). Nuevas oportunidades: participary planificar. Caracas: IREC-EPFL, FPH, Universidad Central de Venezuela.

Lazarini, V. (2007). Los servicios públicos urbanos como medios colectivos para la producción y reproducción de la vida de los sujetos en sociedad desde la perspectiva de la economía social. Análisis de experiencias de gestión colectiva en el Gran Buenos Aires. (Tesis de maestría inédita). Universidad Nacional de General Sarmiento, Buenos Aires.

Levitsky, S. (2003). Transforming Labor-Based Parties in Latin America. Cambridge: Cambridge University Press.

Merlinsky, G., Fernández Bouzo, S., Montera, C., y Tobías, M. (noviembre, 2011). The Right to Water in Buenos Aires: A Long History of Ups and Downs. Conferencia presentada en el seminario Poverty, Water and Local Development, Kampala, Clacso Uganda.

Montera, C. (septiembre, 2012). Lógicas y actores en la gestión de los servicios urbanos. Apuntes sobre la estatización de las redes de agua potable y saneamiento en Buenos Aires. Conferencia presentada en el X Congreso Nacional y 
III Congreso Internacional sobre Democracia. Rosario, Facultad de Ciencia Política y Relaciones Internacionales de la Universidad Nacional de Rosario.

Muñoz, A. (2005). Cooperativas de agua en Argentina. En L. F. Yavary (ed.), Por un modelo público de agua: triunfos, luchas y sueños (pp. 107-112). Madrid: El viejo topo.

Natalucci, A. (2010). Aportes para la discusión sobre la autonomía o heteronomía de las organizaciones sociales. La experiencia del movimiento Barrios de Pie, 2002-2008. Laboratorio, XI (23), 90-108. Recuperado de http://www.lavboratorio.sociales.uba.ar/textos/lavbo23.pdf

Perelmiter, L. (2012). Fronteras inestables y eficaces. El ingreso de organizaciones de desocupados a la burocracia asistencial del Estado. Argentina (2003-2008). Estudios Sociológicos, XXX (89), 431-458.

Pereyra, S., Pérez, G., y Schuster, F. (comps.) (2008). La huella piquetera. Avatares de las organizaciones de desocupados después de 2001. La Plata: Al margen.

Pírez, P. (2004). La configuración metropolitana de Buenos Aires: expansión, privatización y fragmentación. Realidad Económica, (208), 111-134.

Poder Ejecutivo de la Nación Argentina. (2006). Decreto 303 C.F.R. "Rescíndese el Contrato de Concesión suscripto entre el Estado Nacional y la empresa Aguas Argentinas S.A., por culpa del Concesionario”. Ciudad Autónoma de Buenos Aires: Boletín Oficial, 21 de marzo de 2006.

Red Gesol (2014). Nuestra historia: Red Gesol, un modelo de gestión solidaria. Recuperado de http://www.gesol.org.ar/n_historia.htm

Svampa, M., y Pereyra, S. (2003). Entre la ruta y el barrio. La experiencia de las organizaciones Piqueteras. Buenos Aires: Biblos.

Verbitsky, B. (1957). Villa Miseria también es América. Buenos Aires: Kraft Zarazaga, R. (2013). Instituciones, política y necesidad en los programas de transferencias condicionadas: la asignación universal por hijo y el programa de inclusión social con trabajo. En C. Acuña (ed.), ElEstado en acción: fortalezas y debilidades de las politicas sociales (pp. 71-108). Buenos Aires: Siglo XXI.

Zarazaga, R. (s. f.). Brokers beyond Clientelism: A New Perspective on Brokerage through the Argentine Case. Recuperado de http:/ / scholar.harvard.edu/ files/levitsky/files/brokers_beyond_clientelism_19-may-13.pdf 